\title{
Test Series Selection from Nonlinear Neural Mapping
}

\author{
Daniel Domine*, James Devillers \\ CTIS, 21 rue de la Bannière, 69003 Lyon, France \\ Dietrich Wienke and Lutgarde Buydens \\ Catholic University of Nijmegen, Laboratory for Analytical Chemistry, Toernooiveld 1, 6525 ED Nijmegen, The Netherlands
}

\begin{abstract}
A new nonlinear neural mapping (N2M) technique based on the combined use of Kohonen self-organizing map (KSOM), minimum spanning tree (MST), and nonlinear mapping (NLM) is introduced for optimal test series selection. With the N2M method, KSOM results are enhanced by the visualization of the actual distances between the loaded neurons from MST and NLM. N2M provides an easily interpretable and comprehensible graphical display which guides the selection of representative test series especially when the number of individuals is high. In addition, structure-activity relationships can be derived. The approach is open since any information useful for data interpretation can be plotted by means of graphical tools.
\end{abstract}

Key words: nonlinear neural mapping, Kohonen self-organizing map, minimum spanning tree, nonlinear mapping, selection of test series, structure-activity relationships.

\section{Introduction}

The research for new biologically active chemicals in medicinal chemistry requires inspection of several thousands of candidates for which only limited information is available. Since it is practically impossible to test all the possible candidates, a decision must be taken as where to start from. This implies the adoption of strategies for a rational selection of the most relevant compounds for preliminary biological testing and for the derivation of (quantitative) structure-activity relationships ((Q)SARs). This kind of strategies is known as optimal test series design. A lot of work has been directed towards this aim and numerous methods have been proposed [1-3]. Significant advances dealt with the use of linear multivariate methods [4] and linear graphical display methods [5-10] allowing selection of test series by simple visual inspection of 2-D maps summarizing the information content of a matrix of physicochemical properties. Even if these approaches have been successfully used, it was pointed out that from a practical point of view, none of them are completely satisfactory and there is a need for new tools providing complementary information or overcoming methodological problems [2, 3]. In this context, we recently proposed the use of an original graphical approach based on the nonlinear mapping (NLM) method $[2,3,11]$. We showed that it was possible to obtain easily interpretable nonlinear maps of aromatic and aliphatic substituent constants for the selection of test

\footnotetext{
* to receive all correspondence.
}

series and the derivation of SAR. However, it is obvious that when the number of individuals becomes too high, the interpretation of the maps is more difficult. In addition, the selection of optimal test series from nonlinear maps could still be improved if the substituents could be grouped into clusters containing substituents with similar properties. Thus, one could simply select substituent in the clusters in the different regions of a 2-D map. Under these conditions, we propose the use of a newly derived mapping technique called nonlinear neural mapping (N2M) [12] for solving the above problems. This new graphical approach combines the advantages of the Kohonen self-organizing map (KSOM), of the minimum spanning tree (MST), and those of the nonlinear mapping (NLM) method.

\section{Nonlinear Neural Mapping (N2M)}

The N2M algorithm (Figure 1) combines three pattern recognition techniques. First, the Kohonen map forms an initial step for data reduction of $p$ multivariate individuals defined in an $n$-dimensional space into $v$ clusters (loaded neurons). However, information about the correct distances between the neurons disappears during the projection onto the 1,2 , or 3-D array of nodes. One possibility to overcome this distance problem is to add information that allows the simultaneous visualization of the distances between the loaded neurons in the map. The technique recently chosen by Wienke and coworkers [13-16] is a calculation of an MST [17, 18] between the loaded neurons of a trained KSOM in order to visualize the shortest distances between them. These two steps constituted the basis of the 3MAP algorithm designed by Wienke and coworkers [13-16]. As there remains information not represented about the correct distances between all the loaded neurons, in the third step of an N2M analysis, an NLM of the loaded neurons is performed in order to visualize all the distances separating them [12].

\subsection{Kohonen Self-organizing Map (KSOM)}

The Kohonen model of self-organization $[19-21]$ is based on the idea that the brain tends to compress and organize sensory data, spontaneously [22]. A Kohonen network consists of two layers of neurons (i. e., input and output) (Figure 2). The input layer contains $n$ neurons corresponding to the $n$ variables describing the individuals. The output layer can be a 1,2, or 3-dimensional geometrical arrangement of $u$ neurons. In this study, a 2-dimensional array of neurons presenting a square shape was used. The $n$ neurons of the input layer are all connected to each of the $u$ neurons of the output layer so that these $u$ neurons can be considered as $u n$-dimensional 


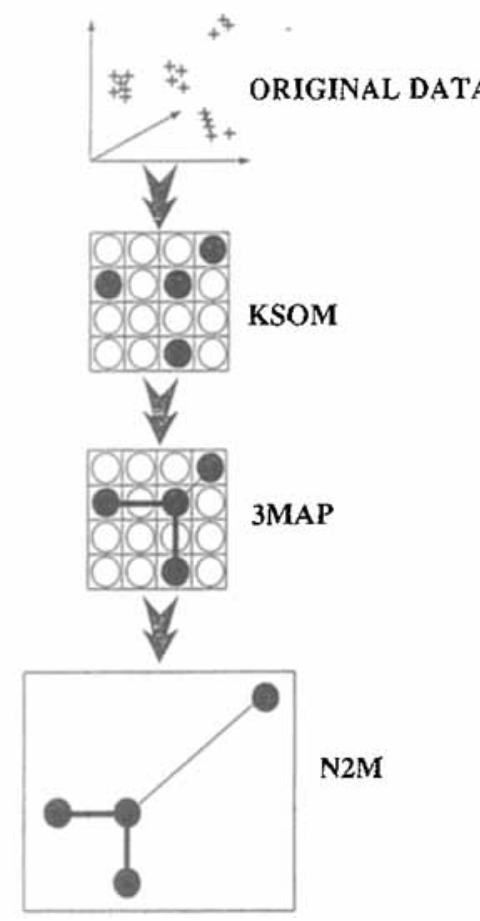

Figure 1. N2M algorithm flow diagram. On the 3MAP, the thickness of the lines is linked to the distance separating the loaded neurons.

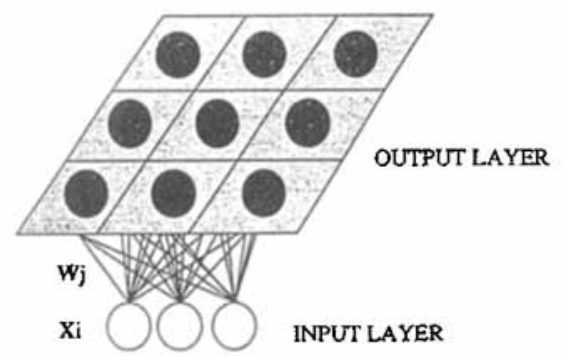

Figure 2. Architecture of a Kohonen network.

weight vectors. The Kohonen algorithm consists in a repeated comparison of the $p n$-dimensional individuals with the $u$ weight vectors using any distance metric such as the Euclidean distance. In the classical algorithm, the weight vectors $\mathbf{W}_{j}$ of the neurons $j$ on the Kohonen map are initialized with small random numbers. In the present study, we used a slightly different method called convex combination $[14,15]$ in which all weights are initialized with a constant value. Then, during each comparison, a winner $\left(W_{c}\right)$ among the $u$ weight vectors can be found. It corresponds to the weight vector having the highest degree of similarity (i. e., smallest distance) with the $i$-th considered individual $X_{\mathbf{i}}$. Then, the $n$ weights connected to the winning neuron $W_{c}$ are updated in order to become closer to the considered individual using the Kohonen learning rule:

$\mathbf{W}_{c}^{\text {new }}=\mathbf{W}_{c}^{\text {old }}+\eta\left(\mathbf{X}_{\mathrm{i}}-\mathbf{W}_{c}^{\text {old }}\right)$

where $\mathbf{W}_{c}^{\text {new }}$ and $\mathbf{W}_{c}^{\text {old }}$ represent the weight vectors of the winning neuron after and before the update, $\mathbf{X}_{i}$ is the $n$-dimensional vector of sample $i$, and $\eta$ is the learning rate with $0<\eta<1$. Together with the winning neuron, $W_{c}$, the nodes that are topologically close in the neuron array up to a certain distance (i.e., within a limited topological neighborhood of radius $\mathrm{R}$ ) activate each other in order to learn from the same input sample. One sequential comparison of all the $p$ samples with all $u$ neural weight vectors and their modification is called one epoch. From one epoch to the next, the neighborhood $\mathrm{R}$ and the learning rate $\eta$ are slightly decreased. They both tend to zero as the number of epochs increases. After repeating the training process over a large number of epochs, a self-organizing behavior of the $p$ samples in the low $m$-dimensional neural array can be observed. They form a visual topological structure. The final result of this training process is an aggregation of subsets of input vectors dedicated to a number $v$ of weight vectors in the neural array with $v \leq u$. Wienke and coworkers [13-16] named these $v$ neurons "loaded neurons". Additional information on KSOM can be found in numerous papers and books [19-34].

\subsection{Minimum Spanning Tree (MST)}

The theory related to the construction of minimum spanning trees has been described by different authors [18]. Briefly, it can be summarized as follows. A set of $p$ objects to be classified the ones in relation to the others, may be considered as a set of points in a space. The representation is classical if the objects are described by a series of $n$ parameters. In that case, one has $p$ points in the $\mathrm{IR}^{\mathrm{n}}$ space. More generally, if one has only the values of an index of dissimilarity, which does not necessarily satisfy the properties of a distance, one may represent the objects as points of a plane, for example. Each couple of objects is then connected by a continuous line to which the value of the dissimilarity index is linked. Thus, the set of objects and the index values are represented by a complete valued graph. However, if the number of objects is too important, this type of representation becomes inextricable.

One may then try to extract from this graph a partial graph having the same nodes but fewer edges. Among all the partial graphs that can be constructed, those that have a tree structure are particularly interesting, since they may be represented on a plane. Thus, a tree is a connected graph (i.e., a line may connect any vertex couple). Moreover, it has no cycle (i. e., one may not have in that tree an edge coming from and converging on the same point without taking twice the same edge).

One may consequently define, in the same way, a tree with $p$ vertices as being a connected graph without a cycle and with $p-1$ edges. The length of a tree is the summation of the length of its edges. An MST is constructed when the length is minimal. Many different algorithms have been proposed for the construction of trees of a minimal length [18]. Readers are advised to consult the article of Devillers and Doré [18] for more information on the theoretical foundations of MST as well as examples of applications. For the N2M technique, we applied the Prim's algorithm [17]. In $\mathrm{N} 2 \mathrm{M}$, this algorithm finds the shortest possible connections between all $v$ loaded neurons with the constraint that no closed connections are allowed.

\subsection{Nonlinear Mapping (NLM)}

$\operatorname{NLM}[35,36]$ allows to represent a set of points defined in an $n$ dimensional space by a human perceivable configuration of the data 
in a lower $m$-dimensional space ( $m=$ two or three) which we will call either display space or nonlinear map. NLM tries to preserve distances between points in the display space as similar as possible to the actual distances in the original space. The procedure for performing this transformation can be summarized as follows.

(i) Interpoint distances in the original space are computed. The Euclidean distance is the most widely used.

(ii) An initial configuration of the points in the display space is chosen. Most often, the coordinates of points in the display space are set in a random manner.

(iii) A mapping error (E) is calculated from distances in the two spaces.

(iv) The coordinates of the points in the display space are iteratively modified by means of a nonlinear procedure so as to minimize the mapping error.

(v) The algorithm terminates when no significant decrease in the mapping error is obtained over the course of several iterations.
In the present study, an Euclidean distance was selected and the steepest descent procedure was used as minimization method $[35,36]$.

Additional information on the practical aspects of the NLM method, a review of its uses in QSAR studies and original examples of applications can be found in previous papers $[2,3,11,36-40]$.

\section{Experimental Section}

An N2M analysis was performed on a set of 103 aliphatic substituents (Table 1) [41] described by means of five substituent constants encoding their hydrophobic, steric, and electronic effects. These parameters were respectively, the hydrophobic constant for aliphatic substituents $\mathrm{Fr}$, the molar refractivity (MR), $\mathrm{H}$-bonding acceptor (HBA) and donor (HBD) abilities, and the inductive parameter $F$. For the $\mathrm{N} 2 \mathrm{M}$ analysis, Fr, MR, and F were centered (i. e., zero mean) and reduced (i. e., unit variance). HBA and HBD were not centered and the " 1 " were replaced by a value yielding a unit variance. This matrix was chosen for its relatively large number of individuals but also because comparison could be made with a recently published NLM analysis of the same data matrix [3].

Table 1. Aliphatic substituents

\begin{tabular}{|c|c|c|c|c|c|}
\hline No. & Substituent & No. & Substituent & No. & Substituent \\
\hline 1 & $\mathrm{Br}$ & 2 & $\mathrm{Cl}$ & 3 & $\mathrm{~F}$ \\
\hline 4 & I & 5 & $\mathrm{NO}_{2}$ & 6 & $\mathrm{H}$ \\
\hline 7 & $\mathrm{OH}$ & 8 & $\mathrm{SH}^{2}$ & 9 & $\mathrm{NH}_{2}$ \\
\hline 10 & $\mathrm{CBr}_{3}$ & 11 & $\mathrm{CCl}_{3}$ & 12 & $\mathrm{CF}_{3}$ \\
\hline 13 & $\mathrm{CN}$ & 14 & SCN & 15 & $\mathrm{CO}_{2}^{-}$ \\
\hline 16 & $\mathrm{CO}_{2} \mathrm{H}$ & 17 & $\mathrm{CH}_{2} \mathrm{Br}$ & 18 & $\mathrm{CH}_{2} \mathrm{Cl}$ \\
\hline 19 & $\mathrm{CH}_{2} \mathrm{I}$ & 20 & $\mathrm{CONH}_{2}$ & 21 & $\mathrm{CH}=\mathrm{NOH}$ \\
\hline 22 & $\mathrm{CH}_{3}^{2}$ & 23 & $\mathrm{NHCONH}_{2}$ & 24 & $\mathrm{OCH}_{3}$ \\
\hline 25 & $\mathrm{CH}_{2} \mathrm{OH}$ & 26 & $\mathrm{SOCH}_{3}$ & 27 & $\mathrm{OSO}_{2} \mathrm{CH}_{3}$ \\
\hline 28 & $\mathrm{SCH}_{3}$ & 29 & $\mathrm{NHCH}_{3}$ & 30 & $\mathrm{CF}_{2} \mathrm{CF}_{3}$ \\
\hline 31 & $\mathrm{C} \equiv \mathrm{CH}$ & 32 & $\mathrm{CH}_{2} \mathrm{CN}$ & 33 & $\mathrm{CH}=\mathrm{CHNO}_{2}$-(trans) \\
\hline 34 & $\mathrm{CH}=\mathrm{CH}_{2}$ & 35 & $\mathrm{COCH}_{3}$ & 36 & $\mathrm{OCOCH}_{3}$ \\
\hline 37 & $\mathrm{CO}_{2} \mathrm{CH}_{3}$ & 38 & $\mathrm{NHCOCH}_{3}$ & 39 & $\mathrm{C}=\mathrm{O}\left(\mathrm{NHCH}_{3}\right)$ \\
\hline 40 & $\mathrm{CH}_{2} \mathrm{CH}_{3}$ & 41 & $\mathrm{OCH}_{2} \mathrm{CH}_{3}$ & 42 & $\mathrm{CH}_{2} \mathrm{OCH}_{3}$ \\
\hline 43 & $\mathrm{SOC}_{2} \mathrm{H}_{5}$ & 44 & $\mathrm{SC}_{2} \mathrm{H}_{5}$ & 45 & $\mathrm{CH}_{2} \mathrm{Si}\left(\mathrm{CH}_{3}\right)_{3}$ \\
\hline 46 & $\mathrm{NHC}_{2} \mathrm{H}_{5}$ & 47 & $\mathrm{~N}\left(\mathrm{CH}_{3}\right)_{2}$ & 48 & $\mathrm{CH}=\mathrm{CHCN}$ \\
\hline 49 & Cyclopropyl & 50 & $\mathrm{COC}_{2} \mathrm{H}_{5}$ & $5 !$ & $\mathrm{CO}_{2} \mathrm{C}_{2} \mathrm{H}_{5}$ \\
\hline 52 & $\mathrm{OCOC}_{2} \mathrm{H}_{5}$ & 53 & $\mathrm{EtCO}_{2} \mathrm{H}$ & 54 & $\mathrm{NHCO}_{2} \mathrm{C}_{2} \mathrm{H}_{5}$ \\
\hline 55 & $\mathrm{CONHC}_{2} \mathrm{H}_{5}$ & 56 & $\mathrm{NHCOC}_{2} \mathrm{H}_{5}$ & 57 & $\mathrm{CH}\left(\mathrm{CH}_{3}\right)_{2}$ \\
\hline 58 & $\mathrm{C}_{3} \mathrm{H}_{7}$ & 59 & $\mathrm{OCH}\left(\mathrm{CH}_{3}\right)_{2}$ & 60 & $\mathrm{OC}_{3} \mathrm{H}_{7}$ \\
\hline 61 & $\mathrm{CH}_{2} \mathrm{OC}_{2} \mathrm{H}_{5}$ & 62 & $\mathrm{SOC}_{3} \mathrm{H}_{7}$ & 63 & $\mathrm{SC}_{3} \mathrm{H}_{7}$ \\
\hline 64 & $\mathrm{NHC}_{3} \mathrm{H}_{7}$ & 65 & $\mathrm{Si}\left(\mathrm{CH}_{3}\right)_{3}$ & 66 & 2-Thienyl \\
\hline 67 & 3-Thienyl & 68 & $\mathrm{CH}=\mathrm{CHCOCH}_{3}$ & 69 & $\mathrm{CH}=\mathrm{CHCO}_{2} \mathrm{CH}_{3}$ \\
\hline 70 & $\mathrm{COC}_{3} \mathrm{H}_{7}$ & 71 & $\mathrm{OCOC}_{3} \mathrm{H}_{7}$ & 72 & $\mathrm{CO}_{2} \mathrm{C}_{3} \mathrm{H}_{7}$ \\
\hline 73 & $\left(\mathrm{CH}_{2}\right)_{3} \mathrm{CO}_{2} \mathrm{H}$ & 74 & $\mathrm{NHCOC}_{3} \mathrm{H}_{7}$ & 75 & $\mathrm{CONHC}_{3} \mathrm{H}_{7}$ \\
\hline 76 & $\mathrm{C}_{4} \mathrm{H}_{9}$ & 77 & $\mathrm{C}\left(\mathrm{CH}_{3}\right)_{3}$ & 78 & $\mathrm{OC}_{4} \mathrm{H}_{9}$ \\
\hline 79 & $\mathrm{CH}_{2} \mathrm{OC}_{3} \mathrm{H}_{7}$ & 80 & $\mathrm{NHC}_{4} \mathrm{H}_{9}$ & 81 & $\mathrm{~N}\left(\mathrm{C}_{2} \mathrm{H}_{5}\right)_{2}$ \\
\hline 82 & $\mathrm{CH}=\mathrm{CHCOC}_{2} \mathrm{H}_{5}$ & 83 & $\mathrm{CH}=\mathrm{CHCO}_{2} \mathrm{C}_{2} \mathrm{H}_{5}$ & 84 & $\mathrm{C}_{5} \mathrm{H}_{11}$ \\
\hline 85 & $\mathrm{CH}_{2} \mathrm{OC}_{4} \mathrm{H}_{9}$ & 86 & $\mathrm{C}_{6} \mathrm{H}_{5}$ & 87 & $\mathrm{OC}_{6} \mathrm{H}_{5}$ \\
\hline 88 & $\mathrm{SO}_{2} \mathrm{C}_{6} \mathrm{H}_{5}$ & 89 & $\mathrm{NHC}_{6} \mathrm{H}_{5}$ & 90 & 2-Benzthiazolyl \\
\hline 91 & $\mathrm{CH}=\mathrm{CHCOC}_{3} \mathrm{H}_{7}$ & 92 & $\mathrm{CH}=\mathrm{CHCO}_{2} \mathrm{C}_{3} \mathrm{H}_{7}$ & 93 & $\mathrm{COC}_{6} \mathrm{H}_{5}$ \\
\hline 94 & $\mathrm{CO}_{2} \mathrm{C}_{6} \mathrm{H}_{5}$ & 95 & $\mathrm{OCOC}_{6} \mathrm{H}_{5}$ & 96 & $\mathrm{NHCOC}_{6} \mathrm{H}_{5}$ \\
\hline 97 & $\mathrm{CH}_{2} \mathrm{C}_{6} \mathrm{H}_{5}$ & 98 & $\mathrm{CH}_{2} \mathrm{OC}_{6} \mathrm{H}_{5}$ & 99 & $\mathrm{CH}_{2} \mathrm{Si}\left(\mathrm{C}_{2} \mathrm{H}_{5}\right)_{3}$ \\
\hline 100 & $\mathrm{CH}=\mathrm{CHC}_{6} \mathrm{H}_{5}$-(trans) & 101 & $\mathrm{CH}=\mathrm{CHCOC}_{6} \mathrm{H}_{5}$ & 102 & Ferrocenyl \\
\hline 103 & $\mathrm{~N}\left(\mathrm{C}_{6} \mathrm{H}_{5}\right)_{2}$ & & & & \\
\hline
\end{tabular}


Different $\mathrm{N} 2 \mathrm{M}$ analyses were performed. Indeed, several sizes of networks were assayed and run for 10000 epochs. During learning the topological radius was regularly decreased during 8000 epochs and trained for further 2000 epochs. The leaming rate $\eta$ was also decreased.

Calculations were performed by means of the 3MAP and STATQSAR packages [42].

\section{Results and Discussion}

\subsection{KSOM Results}

Figure 3 shows the $5 \times 5$ Kohonen map with a final radius of 0 . It is worth noting that by adjusting the size of the network, it was possible to obtain more or less clusters (results not shown). In the present study, a $5 \times 5$ array of neurons provided 19 clusters (Figure 3 ). From Figure 3, it would be possible to select optimal test series by taking one or several substituents in each of the clusters formed. For comparison purposes, we have represented on the KSOM, an example of substituent selection performed in a previous study [3] (underlined bold numbers in Figure 3). It is noteworthy that the results obtained are in accordance with those previously obtained since there is only one (or two) substituent(s) selected per neuron. There remain neurons with no selected substituents. These neurons can be used if a larger set of substituents is required. Figure 4 which shows the projection of the KSOM clusters on the nonlinear map recently derived [3] clearly indicates the complementarity of the two methods. Indeed, KSOM allows to define clusters which are coherent with the nonlinear map. This may help to divide the nonlinear map into a given number of zones from which selection of optimal test series can be made by picking up one or several substituents depending on the population of the clusters and the repartition of the substituents on the map.

\begin{tabular}{|c|c|c|c|c|}
\hline $\begin{array}{l}\text { A } \\
\frac{5}{27,}, \frac{13}{36}, 26,43, \\
62\end{array}$ & 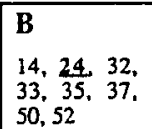 & $\begin{array}{l}\mathrm{C} \\
41,48,51, \\
59,68,70\end{array}$ & $\begin{array}{l}\mathbf{D} \\
69,71,72, \\
78,82\end{array}$ & $\begin{array}{l}\mathrm{E} \\
\frac{87}{93,94}, 91,91,\end{array}$ \\
\hline & & $\begin{array}{l}47,60 \\
5\end{array}$ & $\begin{array}{l}\text { G } \\
83,92\end{array}$ & $\begin{array}{l}\mathbf{H} \\
90,95,101\end{array}$ \\
\hline $\begin{array}{l}\text { I } \\
1,2,3,4,6, \\
1,12,18, \\
28,30,31, \\
34,44\end{array}$ & $\begin{array}{l}\mathbf{J} \\
17,22\end{array}$ & $\begin{array}{l}\mathbf{K} \\
42,61,79, \\
8 \mathbf{L}, 85\end{array}$ & $\begin{array}{l} \\
98\end{array}$ & $\begin{array}{l}\mathbf{M} \\
99,102,103\end{array}$ \\
\hline $\begin{array}{l}\mathbf{N} \\
8\end{array}$ & & & & $\begin{array}{l}\mathrm{O} \\
10,45,65, \\
84,97,100\end{array}$ \\
\hline $\begin{array}{l}\mathbf{P} \\
7,9,15,16, \\
20,21,23, \\
38,39,55, \\
56\end{array}$ & $\begin{array}{l}\mathbf{Q} \\
25,29,54, \\
74,75\end{array}$ & $\begin{array}{l}\mathbf{R} \\
46,53,64, \\
73,80,89, \\
\mathbf{2 6}\end{array}$ & & \begin{tabular}{|l}
$\mathbf{S}$ \\
$19,40,49$, \\
$57,58,63$, \\
$66,67,76$ \\
77,86
\end{tabular} \\
\hline
\end{tabular}

Figure 3. KSOM of aliphatic substituents. Underlined bold numbers represent the substituents selected in a previous study [3].

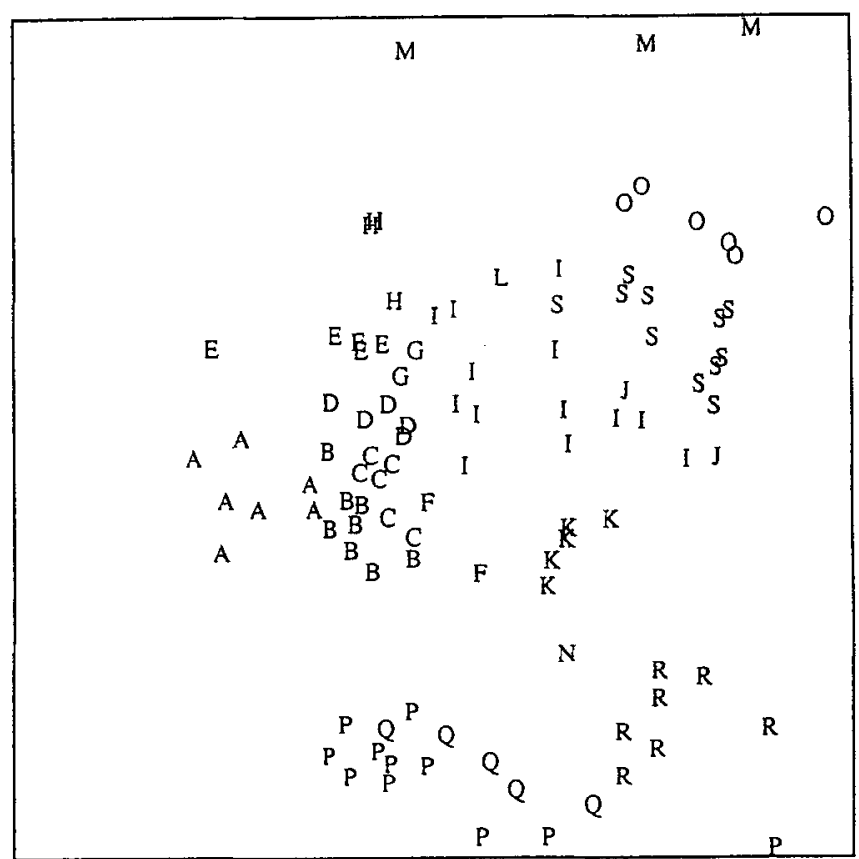

Figure 4. Representation of the KSOM clusters on the nonlinear map [3] See Figure 3 for correspondence between the letters and the clusters. This figure has to be compared with Figure 2, page 982 of the article of Domine $e t$ al. [3].

\subsection{N2M Display}

Even if a map with 103 substituents remains relatively easy to inspect and interpret, it is obvious that there are limitations in the number of points which can be displayed on a 2-D map. Therefore, the N2M display, which is a nonlinear mapping of the loaded

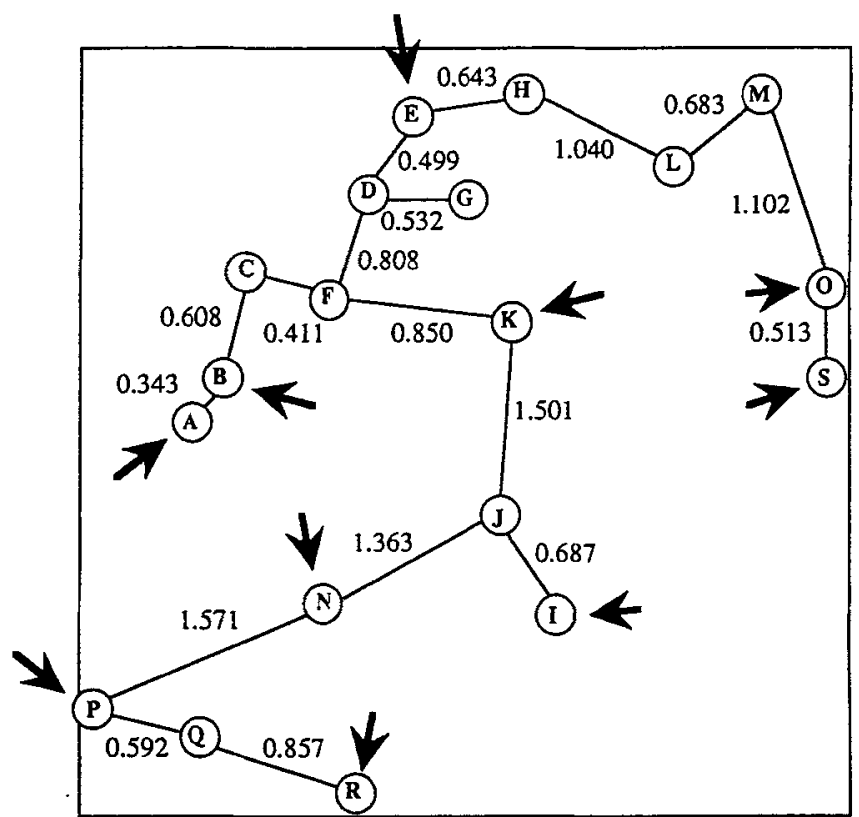

Figure 5. N2M display of aliphatic substituents. The values reported are the actual distances in the MST. See Figure 3 for correspondence between the letters and the clusters. See text for the significance of the arrows. 
neurons on which an MST has also been projected, allows to reduce the number of points to a few number of clusters (loaded neurons) and take into account the distances separating the different clusters. Inspection of the N2M display (Figure 5) indicates that the topology of the Kohonen map is kept. Thus, for example, it can be noted that the alignment of neurons $A$ to $E$ is preserved on Figure 5. One can also note that neuron $F$ is located between neurons $C$ and $K$. The same remark can be made for all other neurons. The only slight divergence is observed for neuron I. Indeed, it can be noted that $\mathrm{I}$ is no longer between neurons $\mathrm{A}$ and $\mathrm{N}$ on the N2M display. In this case, the map which preserved the actual distances between the neurons lost the correct topology. However, it must be noted that this loss does not concern three adjacent neurons and that the alignment of the three adjacent neurons I, J, and $\mathrm{K}$ for example is kept. Projection of the MST allows to underline the shortest distances between the loaded neurons.

\subsection{Graphical Interpretation and Chemical Significance of the N2M Display}

To facilitate the interpretation of the $\mathrm{N} 2 \mathrm{M}$ results and also the selection of optimal sets, graphical tools can be used. Thus, for example, it is possible to represent the weight vectors of the neurons by means of collections of graphs where the larger the squares the higher the values of the weights for each variable and the larger the circles the lower the values of the weights (Figure 6). In Figure 6, for example, we can underline that the neurons located in the bottom left-hand part of the map (i. e., neurons $\mathrm{P}, \mathrm{Q}$, and $\mathrm{R}$ ) are associated with large weight values for the HBD descriptor (Figure 6.3) and low weight values for the Fr (Figure 6.1) and MR (Figure 6.4) descriptors. From a general point of view, the collection of graphs displayed in Figure 6 explains the repartition of the clusters on the map. Indeed, as the weight vectors are generally representative of the properties of the substituents included in each cluster (i.e., loaded neuron), Figure 6 gives a fair view of the repartition of the clusters with regards to the physicochemical properties of the substituents they contain. It is obvious that a better description could be obtained by plotting the actual properties but the weight vectors generally represent a good first approximate.

In order to give a full description of the N2M display in terms of structural information and underline structure-property relationships for the 103 aliphatic substituents under study, various structural features have been reported on the N2M display (Figure 7). Thus, a series of graphs was drawn on which was represented the presence of substituents containing given functional groups. Figure 7 shows the relative position of the clusters as well as the coherence of the map from a chemical point of view. Figure 7.1 shows that substituents containing primary or secondary amine groups are all located in clusters $\mathrm{P}, \mathrm{Q}$, and $\mathrm{R}$. Comparison with Figure 6 reveals that these clusters are characterized by low weight values for $\mathrm{Fr}$ (Figure 6.1) and high weight values for HBD ability (Figure 6.3). Compared with the nonlinear map (results not shown), it is however not possible to separate the substituents with general formula NHR with $R=H$, alkyl, or phenyl (no. 9, 29, 46, 64, 80, and 89 ) from the other substituents containing a carbonyl group (no. $20,23,38,39,54-56,74,75$, and 96 ).

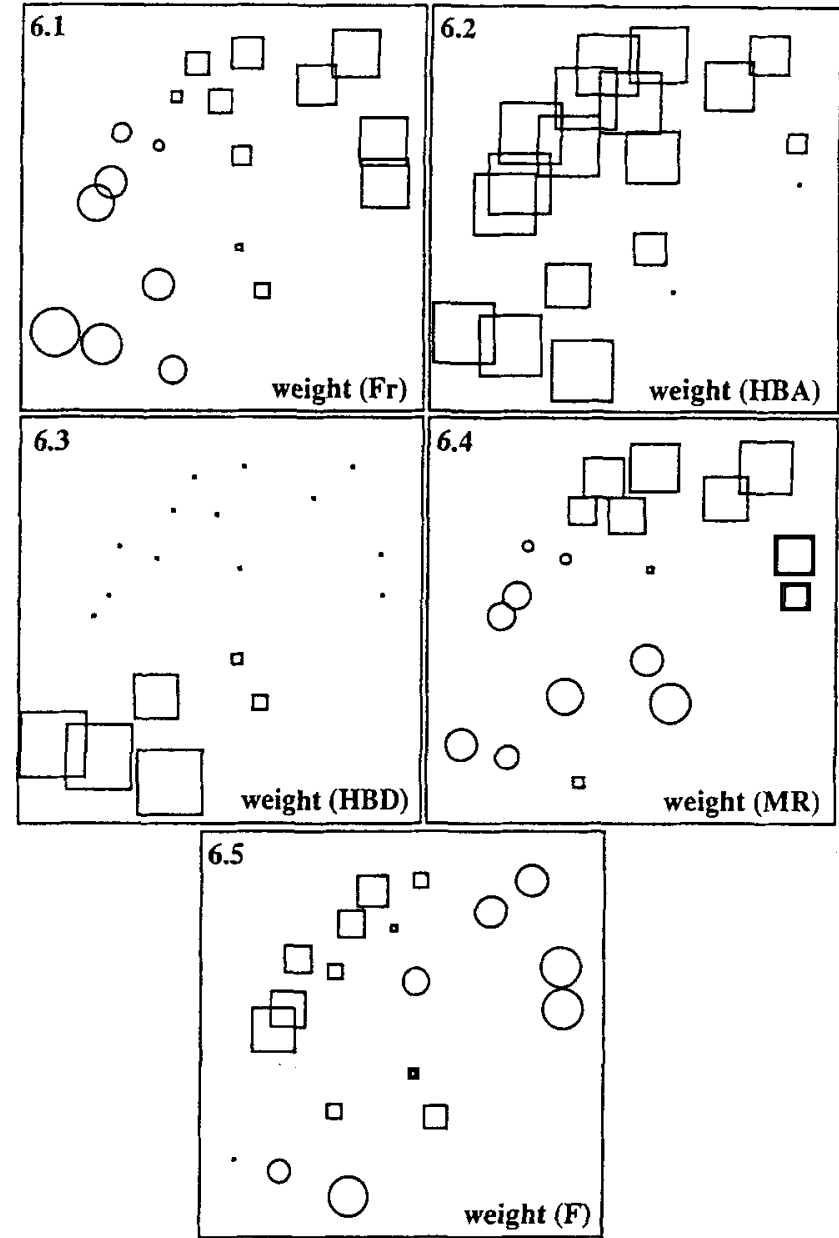

Figure 6. Plot of the weight values linked to the five descriptors on each cluster of the N2M display (Figure 5). Squares (positive values) and circles (negative values) are proportional in size to the magnitude of the weights.

In Figure 7.2, we have represented in black the clusters containing substituents having $\mathrm{CN}$ or $\mathrm{NO}_{2}$ groups in their structure. All the substituents containing these groups (no. $5,13,14,32,33$, and 48 ) are located in the same region of the N2M display in clusters A, B, and C. Comparison of Figure 7.2 with Figure 6.1 shows that this location can be explained by low weights for Fr. In addition, these substituents have the ability to accept but not to donate $\mathrm{H}$ bonds.

Figure 7.3 shows that the distribution of the clusters containing substituents with an -S-group is less obvious and presents slight differences with the distribution observed on the nonlinear map [3]. Even if we still observe in separated clusters substituents no. 8 and 90 (clusters $\mathrm{N}$ and $\mathrm{H}$, respectively), the distribution of the other substituents is less obvious. The cyclic substituents no. 66 and 67 (i.e., 2- and 3-Thienyl) can be found in a same cluster (S) together with $\mathrm{SC}_{3} \mathrm{H}_{7}$ (no. 63). $\mathrm{SCH}_{3}$ (no. 28) and $\mathrm{SC}_{2} \mathrm{H}_{5}$ (no. 44) are in cluster $\mathrm{I}$.

Figure 7.4 represents the presence of substituents containing $\mathrm{C}=\mathrm{O}$ or $\mathrm{C}=\mathrm{S}$ groups in the clusters. These clusters can be separated into two groups, i. e., clusters $A, B, C, D, E, G$, and $\mathrm{H}$ at the top of the 


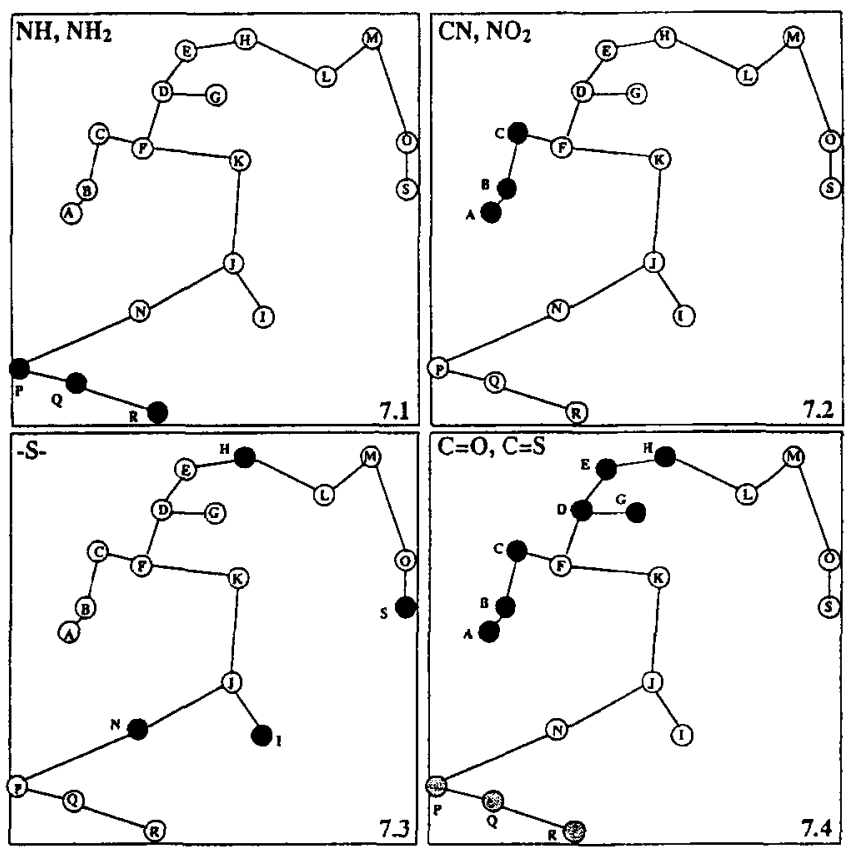

Figure 7. Representation of functional groups on the N2M display (Figure 5). Presence of substituents with a given structural feature is indicated in black or grey. See text for interpretation.

Figure and clusters $P, Q$, and $R$ at the bottom. The $C=O$ and $C=S$ substituents in the former group can only accept $\mathrm{H}$-bonds while those of the latter group are characterized by $\mathrm{HBA}$ and $\mathrm{HBD}$ abilities (Figures 6.2 and 6.3). Only substituent no. $15\left(\mathrm{CO}_{2}^{-}\right)$whose atypical location was stressed in an earlier study [3] transgresses this rule.

In the same way, it could be possible to plot any other structural information on the N2M display as done above. This would help to locate the different types of substituents and have a complete view of its constitution to facilitate the selection of highly informative test series.

\subsection{Selection of Test Series}

As shown above, the N2M display (Figure 5) gives a full description of the data structure in the starting population and it is chemically coherent since the repartition of the substituents can be directly linked to their chemical structure. Therefore, from a practical point of view, Figure 5 represents a very useful basis for the selection of optimal test series. Indeed, by picking up one or several substituents in each of the clusters, it is possible to obtain a highly representative series of substituents in terms of physicochemical properties. In addition, if substituents present in a given cluster are difficult to synthesize or not useful for a QSAR study (due to being atypical, as for cluster M), it is possible to select substituents in the nearest cluster(s) from a simple visual inspection of the nonlinear neural map (Figure 5). Another advantage of the MST is that it can guide the precise selection of candidates. Thus, for example, if we consider that a substituent in cluster J (Figure 5) has to be replaced by a substituent in another cluster, the MST suggests cluster I. For comparison purposes, by means of arrows, we have represented on Figure 5 a selection of substituents proposed in a previous study [3]. It is noteworthy that the results obtained are in accordance with those previously published [3] since there is only one (or two) substituent(s) selected per neuron and the selected neurons cover well the space. Note that other combinations are possible depending on the goal of the study. Indeed, it must be noted that the selection of a test series cannot be universal and always depends on the studied activity and on the knowledge we have on it.

$\mathrm{N} 2 \mathrm{M}$ can facilitate the selection of substituents for the constitution of non redundant test series. This can simply be done by inspection of the map (Figure 5) by eye. Since it is possible to obtain different test series on the same map, synthetic feasibility or previous knowledge on the considered activity can always adequately be taken into account. N2M provides a very simple and straightforward representation of the results in line with classical chemical thinking which should be attractive to synthetic chemists. Furthermore, the 2-D map gives a full picture of the data structure in the starting population which cannot be obtained with classical linear multivariate methods. Compared with classical NLM, the advantages of the clustering method and the display technique simplify the map and guide the selection.

\subsection{Deriving Structure-Activity Relationships from the N2M Dis- play}

$\mathrm{N} 2 \mathrm{M}$ is particularly suitable for underlining relationships between the structure of the molecules and their biological response(s). For illustrative purposes, an example dealing with the antifungal activity (i. e., $\mathrm{pI}_{50}=\log \left(1 / I_{50}\right)$ where $\mathrm{I}_{50}$ values express the molar concentration of chemical for $50 \%$ inhibition of mycelial growth) of 1 (3,5-dichlorophenyl)-3-substituted-2,5-pyrrolidinediones against Botrytis cinerea is presented (Figure 8) [43]. From a set of 22 $\mathrm{pl}_{50}$ values [43], we kept the 12 values corresponding to substituents contained in our set. It has to be noted that the remaining ten substituents did not carry much more information and that the 12 selected substituents were representative of the set. The N2M clusters containing these 12 substituents are shown in Figure 8 . Inclusion of the 12 substituents in only four clusters (Figure 8) indicates that the selection made by the authors [43] was not representative of the whole physicochemical space. Despite this, Figure 8 underlines relationships between the structure and the antifungal activity of the studied chemicals. Thus, the least active substituents both containing an $\mathrm{S}=\mathrm{O}$ group are included in cluster $\mathrm{A}$. Clusters I and $J$ contain alkyl and thioether substituents which are more active. The most active substituents being alkyls, phenyl, and thioethers with a size larger than the alkyls and thioethers found in clusters $\mathrm{I}$ and $\mathrm{J}$, are included in cluster S. Comparison of Figure 8 with Figure 6 shows, for example, that the antifungal activity increases with hydrophobicity and MR (Figures 6.1 and 6.4 , respectively). Decreasing F values (Figure 6.5) also seem to increase the antifungal activity. These results confirm those published in the literature [43] which showed, from classical regression equations, a relationship between the antifungal activity of 1-(3,5-dichlorophenyl)-3substituted-2,5-pyrrolidinediones and $\log$ P. A new examination of these data revealed that both the size of the substituents and their dipole moment were also important [44]. 


\section{Concluding Remarks}

The purpose of our study is not to advance that N2M is the new panacea for solving the complex task of substituent selection. We only show that N2M is a powerful tool in the kit of chemometric methods providing useful information for selecting substituents. Indeed, in drug design, it is essential to select test series with high information content in order to reduce the costs in research by maximizing the information content obtained from each molecular probe in a set of congeners. In the same way, for the derivation of valuable QSAR from reduced sets of compounds, selection of sets presenting a maximum meaningful variety is necessary. Therefore, a lot of work have been directed towards this aim and many authors have proposed different methods. Among them, factorial design and $D$-optimal design have proved to be successful in many applications [e.g., 1, 45, 46]. However, practical problems arise when the dimensionality of data matrices becomes too high since visual inspection of the different factorial planes is a long and tedious task. In addition, when the number of individuals becomes high, the maps appear as galaxies of points hardly interpretable. N2M addresses these two problems since the use of a nonlinear technique allows one to obtain a single easily interpretable map and the use of a clustering technique prior the mapping allows one to obtain easily readable maps with fewer numbers of "points". In the present paper, to stress the heuristic potency of N2M, an example containing 103 substituents described by five physicochemical variables has been presented but the technique has also been successfully applied to a data matrix containing 604 chemicals described by nine variables [47]. It is also noteworthy that our approach is open and allows the graphical representation of any information susceptible to help in the interpretation of the results.

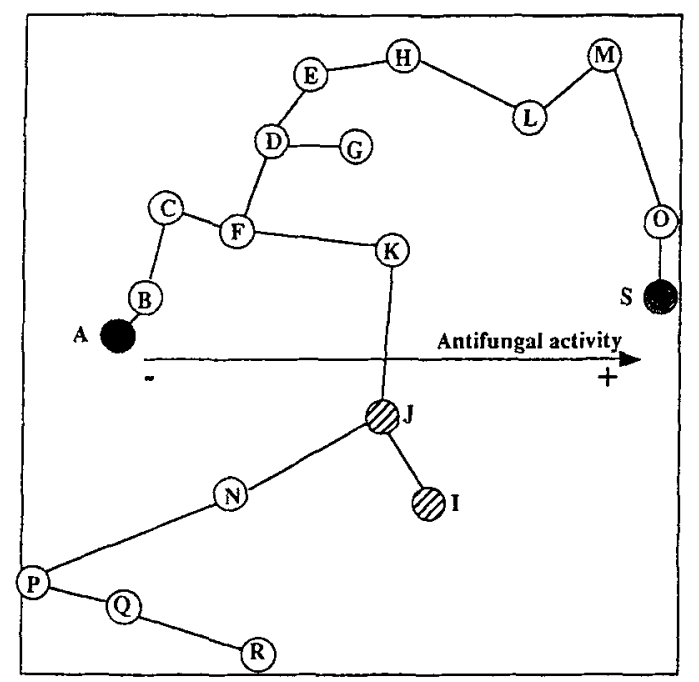

Figure 8. Representation of the antifungal activity of twelve 1-(3,5-dichlorophenyl)-3-substituted-2,5-pyrrolidinediones against Botrytis cinerea. The measured activity was the concentration inducing $50 \%$ inhibition of mycelial growth $\left(10^{\left.-\mathrm{pl}_{50}\right)}\right.$ [43]. The cluster in black contains two substituents having an $\mathrm{SO}$ group in their constitution (i. e., no. $26\left(\mathrm{SOCH}_{3}\right)$ and $62\left(\mathrm{SOC}_{3} \mathrm{H}_{7}\right)$ ) whose values of $10^{-\mathrm{pI}_{50}}\left(\mu \mathrm{mol}^{-1}\right)$ are superior to 5 . The clusters with striped lines contain substituents no. $6(\mathrm{H}), 22\left(\mathrm{CH}_{3}\right), 28\left(\mathrm{SCH}_{3}\right)$, and $44\left(\mathrm{SC}_{2} \mathrm{H}_{5}\right)$ whose values of $10^{-\mathrm{pl}_{50}}$ values $\left(\mu \mathrm{mol} \mathrm{1} \mathrm{I}^{-1}\right)$ range from 2.09 to 3.24 . The cluster in light grey contains larger substituents (i.e., no. $40\left(\mathrm{CH}_{2} \mathrm{CH}_{3}\right), 57$ $\left(\mathrm{CH}\left(\mathrm{CH}_{3}\right)_{2}\right), 58\left(\mathrm{C}_{3} \mathrm{H}_{7}\right), 63\left(\mathrm{SC}_{3} \mathrm{H}_{7}\right), 76\left(\mathrm{C}_{4} \mathrm{H}_{9}\right)$, and $\left.86\left(\mathrm{C}_{6} \mathrm{H}_{5}\right)\right)$ whose values of $10^{-p 1} \mathrm{I}_{50}\left(\mu \mathrm{mol} \mathrm{I}^{-1}\right)$ range from $\mathrm{I}$ to 2.00 .

\section{References}

[1] Pleiss, M.A. and Unger, S.H., in: Ramsden, C.A. (Ed.), Comprehensive Medicinal Chemistry, Vol. 4, Pergamon Press, Oxford 1990, pp. 561587.

[2] Domine, D., Devillers, J. and Chastrette, M., J. Med. Chem. 37, 973980 (1994).

[3] Domine, D., Devillers, J. and Chastrette, M., J. Med. Chem. 37, 981987 (1994).

[4] Hansch, C., Unger, S.H. and Forsythe, A.B., J. Med. Chem. 16, $1217-$ 1222 (1973).

[5] Dove, S., Streich, W.J. and Franke, R., J. Med. Chem. 23, 1456-1459 (1980).

[6] Alunni, S., Clementi, S., Edlund, U., Johnels, D., Hellberg, S., Sjöström, M. and Wold, S., Acta Chem. Scand. B 37, 47-53 (1983).

[7] van de Waterbeemd. H., El Tayar, N., Carnupt, P.A. and Testa, B., J. Comput.-Aided Mol. Design 3, 111-132 (1989).

[8] Tosato, M.L. and Geladi, P., in: Karcher, W. and Devillers, J. (Eds.), Practical Applications of Quantitative Structure-Activity Relationships (QSAR) in Environmental Chemistry and Toxicology, Kluwer Academic Publishers, Dordrecht 1990, pp. 317-341.

[9] Baroni, M., Clementi, S., Cruciani, G., Kettaneh-Wold, N. and Wold, S., Quant. Struct. Act. Relat. 12, 225-231 (1993).

[10] Caliendo, G., Greco, G., Novellino, E., Perissutti, E. and Santagada, V., Quant. Struct. Act. Relat. 13, 249-261 (1994).

[11] Devillers, J., in: van de Waterbeemd, H. (Ed.), Chemometric Methods in Molecular Design, VCH, Weinheim 1995, pp. 255-263.

[12] Domine, D., Wienke, D., Devillers, J. and Buydens, L., in: Devillers, J. (Ed.), Neural Networks in QSAR and Drug Design, Academic Press. London 1996, pp. 223-253.

[13] Wienke, D., Gao, N. and Hopke, P.K., Environ. Sci. Technol. 28, $1023-$ 1030 (1994).

[14] Wienke, D. and Hopke, P.K., Anal. Chim. Acta 291, 1-18 (1994).

[15] Wienke, D. and Hopke, P.K., Environ. Sci. Technol. 28, 1015-1022 (1994).

[16] Wienke, D., Xie, Y. and Hopke, P.K., Anal. Chim. Acta 310, 1-14 (1995).

[17] Prim, R.C., Bell Syst. Technol. J. 36, 1389-1401 (1957).

[18] Devillers, J. and Doré, J.C. Ecotoxicol. Environ. Safety 17, 227-235 (1989).

[19] Kohonen, T., Self-Organization and Associated Memory, Springer-Verlag, Heidelberg 1989.

[20] Kohonen, T., Proc. IEEE 78, 1464- 1480 (1990).

[21] Kohonen, T., Hynninen, J., Kangas, J. and Laaksonen, J., SOM_PAK. The Self-Organizing Map Program Package, Version 3.1 (April 7, 1995), SOM Programming Team of the Helsinki University of Technology: Laboratory of Computer and Information Science, Espoo, Finland 1995.

[22] Zeidenberg, M., Neural Networks in Artificial Intelligence, Ellis Horwood Limited, Chichester 1990.

[23] Eberhart, R.C. and Dobbins, R.W., Neural Network PC Tools: A Practical Guide, Academic Press, San Diego 1990.

[24] Arrigo, P., Giuliano, F., Scalia, F., Rapallo, A. and Damiani, G., Comput. Appl. Biosci. 7, 353-357 (1991).

[25] Ferran, E.A. and Ferrara, P., Biol. Cybern. 65, $451-458$ (1991).

[26] Ferran, E.A. and Ferrara, P., Comput. Appl. Biosci. 8, 39-44 (1992).

[27] Ferran, E.A. and Ferrara, P., Physica A 185, 395-401 (1992).

[28] Rose, V.S., Croall, I.F. and MacFie, H.J.H., Quant. Struct. Act. Relat. $10,6-15(1991)$.

[29] Ferran, E.A. and Pflugfelder, B., Comput. Appl. Biosci. 9, 671-680 (1993).

[30] Melssen, W.J., Smits, J.R.M., Rolf, G.H. and Kateman, G., Chemom. Intell. Lab. Syst. 18, 195-204 (1993).

[31] Zupan, J. and Gasteiger. J., Neural Networks for Chemists. An Introduction, VCH, Weinheim 1993.

[32] Bienfait, B., J. Chem. Inf. Comput. Sci. 34, 890-898 (1994). 
[33] Thoreau, E., Modélisation par Homologie du Domaine de Liaison à l'Hormone des Récepteurs Hormonaux Nucléaires à Partir de l'Hypothèse "Serpin". Contributions au Développement de la Méthode HCA, Ph. D. Thesis, Paris VII, France, 1994.

[34] Barlow, T.W., J. Mol. Graphics 13, 24-27 (1995).

[35] Sammon, J.W., IEEE Trans. Comput. C.18, $401-409$ (1969).

[36] Domine, D., Devillers, J., Chastrette, M. and Karcher, W., J. Chemometrics 7, 227-242 (1993).

[37] Domine, D., Devillers, J., Garrigues, P., Budzinski, H., Chastrette, M. and Karcher, W., Sci. Total Environ. 155, 9-24 (1994)

[38] Devillers, J., Domine, D. and Bintein, S., SAR QSAR Environ Res. 2. 261-270 (1994)

[39] Domine, D., Devillers, J., Chastrette, M. and Doré J.C., in: Reynolds, C.H., Holloway, M.K. and Cox, H.K. (Eds.), Computer-Aided Molecular Design. Applications in Agrochemicals, Materials, and Pharmaceuticals, ACS Symposium Series no. 589, American Chemical Society, Washington, DC 1995, pp. 267-280.

[40] Domine, D. and Devillers. J. SAR QSAR Environ. Res. 4, 51-58 (1995).

[41] Hansch, C. and Leo, A., Substituent Constants for Correlation Analysis in Chemistry and Biology, John Wiley \& Sons, New York 1979.

[42] 3MAP and STATQSAR are homemade software. Information on 3MAP can be obtained from Dr. D. Wienke at the University of Nijmegen. STATQSAR is commercially available upon request to CTIS, 21 rue de la Bannière, 69003 Lyon, France. However, note that N2M combines three algorithms which are widely described in the literature and directly available as source code on the Internet. Thus, for example, the best way for obtaining the KSOM is to use the following FTP con- nection: cochlea.hut.fi (130.233.168.48). An NLM program is aiso available at this address. In addition, the complete NLM algorithm with formulas of parameters specifically designed for QSAR studies is provided in Domine et al. ( $J$. Chemometrics 7, 227-242 (1993)). Last, the MST algorithm can be obtained at the following address: http://biomserv.univ-lyon l.fr/ADE-4.html. In addition, numerous information on the different MST algorithms available in the literature can be found in Devillers and Doré (Ecotoxicol. Environ. Safety 17, $227-235$ (1989)).

[43] Takayama, C., Fujinami, A., Kirino, O. and Hisada, Y., Agric. Biol. Chem. 46, 2755-2758 (1982).

[44] Li, W.Y., Guo, Z.R., and Lien, R.J., J. Pharm. Sci. 73, 553-558 (1984).

[45] Clementi, S., Cruciani, G., Baroni, M., and Costantino, G., in: Kubinyi, H. (Ed.), 3D QSAR in Drug Design. Theory, Methods and Applications, ESCOM, Leiden 1993, pp. 567-582.

[46] Sjöström, M. and Eriksson, L., in: van de Waterbeemd, H. (Ed.), Che mometric Methods in Molecular Design, VCH, Weinheim 1995, pp. 63-90.

[47] Domine, D. and Devillers. J., Extracting Information from Large Data Sets by Means of Nonlinear Neural Mapping, Oral Presentation, Symposium on Neural Networks in Chemistry (Organizer: J. Gasteiger), 211 th ACS National Meeting, New Orleans, LA, USA March 24 $28,1996$.

Received on April 7th 1996; accepted on June 18th 1996. 